\title{
Accurate Flexible Temperature Sensor Based on Laser-Induced Graphene Material
}

\author{
Huang Kun, ${ }^{1,2}$ Liu Bin, ${ }^{2}$ Mostafa Orban $\mathbb{D}^{1,2,3}$ Qiu Donghai, ${ }^{2}$ and Yang Hongbo $\mathbb{D}^{1,2}$ \\ ${ }^{1}$ School of Biomedical Engineering (Suzhou), Division of Life Sciences and Medicine, \\ University of Science and Technology of China, Hefei, Anhui 230026, China \\ ${ }^{2}$ Suzhou Institute of Biomedical Engineering and Technology, Chinese Academy of Sciences, Suzhou, Jiangsu 215163, China \\ ${ }^{3}$ School of Mechanical Engineering, Shoubra Faculty of Engineering, Benha University, Benha, Qaliobia 13518, Egypt \\ Correspondence should be addressed to Yang Hongbo; yanghb@sibet.ac.cn
}

Received 18 March 2021; Accepted 26 May 2021; Published 17 June 2021

Academic Editor: Yiwei Wang

Copyright (C) 2021 Huang Kun et al. This is an open access article distributed under the Creative Commons Attribution License, which permits unrestricted use, distribution, and reproduction in any medium, provided the original work is properly cited.

\begin{abstract}
Body temperature is an essential physiological index reflecting human health. Accurate measurements of body temperature play a vital role in the diagnosis and treatment of diseases. In this paper, a temperature sensor manufactured by laser-induced graphene is introduced. This sensor has high measurement accuracy, simple preparation, and low production cost. The sensor is made of laser-induced graphene and is easier to fabricate and operate than traditional thermal resistance sensors. The sensor is of high accuracy, is easy to manufacture, and is of low cost. The sensor has high accuracy and is linear between $30^{\circ} \mathrm{C}$ and $40^{\circ} \mathrm{C}$ in the human body temperature ranges. Laser-induced graphene (LIG) sensor's resistance value is correlated linearly with the temperature value, and compared with the infrared thermometer, the accuracy of the sensor is $\pm 0.15^{\circ} \mathrm{C}$ while that of the infrared thermometer is $\pm 0.30^{\circ} \mathrm{C}$. The sensitivity of the LIG sensor is $-0.04145 \%{ }^{\circ} \mathrm{C}^{-1}$.
\end{abstract}

\section{Introduction}

Body temperature measurement is an important physiological parameter that reflects the health of the human body, and its accuracy affects the diagnosis and treatment of diseases. Nowadays, equipment used for measuring body temperature is mainly mercury thermometers and electronic thermometers $[1,2]$. Due to the shortcomings of mercury thermometers, they are replaced gradually by convenient electronic thermometers [3]. The main types of current electronic thermometer sensors include platinum resistance sensors, integrated temperature sensors, thermocouple sensors, and thermistor sensors [4]. These clinical thermometers are made of rigid materials which are prone to relative displacement with human skin during the measurement process. This relative displacement leads to inaccurate measurements and limits the application scenarios of body temperature detection. The flexible sensor uses materials similar to Young's modulus of human skin. It has the advantages of being bendable and extensible and can maintain common contact with the human body. The flexible sensor is used for daily personal health monitoring and treatment, human body temperature detection, and sports rehabilitation treatment [5-8].

Flexible sensors are proved to have good effects in the field of human life characteristics. For example, in detecting bioelectric signals, the flexible sensor can detect various physiological diseases (such as cerebral thrombosis and arrhythmia and other cardiovascular and cerebrovascular diseases) and is used for diagnosis and prevention of diseases. Flexible sensors are also used to detect EMG and EEG signals, which can be used to research intelligent prosthetics, rehabilitation medicine, sleep monitoring, and other fields. Compared with the traditional wet electrode, semidry electrode, and hard-dry electrode, the flexible sensor has less skin stimulation. Combining the skin is more stable, which greatly expands its application scenarios [9-13].

Flexible temperature sensors have different types, such as thermocouple type and thermal resistance type [14]. Zeng manufactured a temperature sensor using a "sandwich" structure, which used PEO as a temperature-sensitive 
material, used PVDF as a matrix, and used graphite powder as a conductive filler. The manufacturing process is as follows: manufacture PVDF/PEO material while preparing silica gel substrate, then cut and manufacture PVDF/PEO material film and lead out the electrode connections, and finally cast liquid PDMS and spin-coated poured to form an outside film [15]. Dankoco et al. used an organic silver composite (TEC-IJ-010) thermistor, deposited on a polyimide film by inkjet printing, to make a type of thermistor for medical applications [16]. Karimov et al. produced a flexible temperature sensor based on carbon nanotubes. The manufacturing process is to deposit carbon nanotube powder on a $35 \mu \mathrm{m}$ adhesive elastic polymer belt, build the aluminum foil electrode into the polymer tape, and then cover it with the same kind of tape and make it act as an elastic sleeve [17]. Xiao et al. have successfully developed an array of platinum thin-film thermistors. They used liquid spin-coated polyimide flexible substrates. The manufacturing process is as follows: oxidize the silicon wafer thermally to generate a $\mathrm{SiO}_{2}$ sacrificial layer with appropriate thickness, prepare a certain thickness of a polyimide film, and then sputter a Ti/W alloy adhesion layer of $20 \mathrm{~nm}$ and a Pt film of $100 \mathrm{~nm}$. Then pattern by photolithography to form a resistance strip. And then, a Ti/W alloy adhesion layer of $20 \mathrm{~nm}$ and an Au film of 200 are sputtered and photolithographed to form electrodes. Next, it is covered with PAA protective layer. The device is released on the flexible substrate [18].

The traditional manufacturing process of flexible temperature sensors mainly includes functional material preparation, nanoscale functional film deposition, micronano structure patterning, transfer printing, and packaging. The process is complex, and the manufacturing cycle is long. The manufacturing process requires well-trained operators and a variety of equipment [19-23]. Laser-induced graphene manufacturing [24] needs simple experimental conditions, a simple patterning process, and lower manufacturing costs. Laser-induced graphene is used to mold Polyimide's surface pattern in one path, and the design can be customized freely. Therefore, laser-induced graphene has a wide range of applications and strong compatibility. This paper introduces a flexible temperature sensor based on laser-induced graphene. Using the thermal sensitivity of graphene, it can accurately measure the human body temperature. The laserinduced graphene (LIG) sensor's advantages are high accuracy, low cost, simple manufacturing process, and ease to achieve mass production. The accuracy of LIG sensor is higher than that of the latest infrared thermometer temperature sensor in the market (Omron infrared thermometer). The rest of this paper is arranged as follows. Section 2 introduces the LIG temperature sensor's working principle and manufacturing process. Section 3 contains the experimental performance work. The first one is the Raman spectroscopy test. Then, the LIG sensor's sensitivity is checked by running an experiment in different conditions $\left(30^{\circ} \mathrm{C}-40^{\circ} \mathrm{C}\right)$ and $\left(30^{\circ} \mathrm{C}-60^{\circ} \mathrm{C}\right)$ using a temperature table. A real application test for the LIG sensor with three human volunteers is used to evaluate the LIG sensor's applicability with the human body. Finally, an experiment verifies LIG sensor's higher accuracy by comparing the LIG sensor recordings with the most accurate temperature sensor in the market (Omron infrared thermometer), and thermocouple readings are used as reference readings. Section 4 presents experimental results and discussion. Section 5 contains the conclusion of this paper.

\section{LIG Sensor Theory and Manufacturing Process}

2.1. LIG Sensor Theory. Graphene is a single-layer two-dimensional honeycomb structure material composed of carbon atoms connected by $s p^{2}$ hybrids bonds. Also, graphene conductivity is related to the strength of electrophonon coupling within a limited temperature range. As the temperature rises, the electro-phonon coupling increases, leading to increased conductivity and decreased resistance. These characteristics make the graphene material can stand as the graphene temperature sensitivity. This article presents a low cost, small size, and accurate temperature sensor for human body temperature measurement based on the graphene temperature sensitivity.

2.2. Manufacturing Process. The LIG sensor introduced in this paper was manufactured by using a laser-induced method. During the manufacturing process, the laser irradiates the polyimide film to produce energy, making the lattice vibrate. The lattice vibration causes the local high temperature to destroy the $\mathrm{C}-\mathrm{O}, \mathrm{C}=\mathrm{O}$, and $\mathrm{N}-\mathrm{C}$ bonds and cause the aromatic and imide repeating units in the polyimide film to be rearranged to form the graphene. One of the critical successes of this manufacturing process is the manufacturing process before the laser-induced graphene process. The entire manufacturing process is carried out on an acrylic plate to the polyimide film's flatness during the manufacturing process. First, the double-sided tape is pasted on the acrylic board $(100 \mathrm{~mm} \times 100 \mathrm{~mm})$, which is used to fix polyimide e film and acrylic plate in relative position. It is used to position the polyimide film in the processing instrument during the subsequent processing to ensure the pattern's processing accuracy. A hydrosol tape (ASWT2, a width of $5 \mathrm{~cm}$, Aquasol) is attached between the polyimide film and double-sided tape to ensure complete fixation of the sensor during all the fabrication processes. Then, a polyimide film $\left(50 \times 10^{-3} \mathrm{~mm}\right.$ thickness, Kapton $\left.\mathrm{HN}\right)$ is pasted on the hydrosol tape. In the above three steps, it is necessary to ensure that the two layers of materials are bonded smoothly without any bubbles or bulges in between. In the processing stage, the polyimide film is written directly by a $\mathrm{CO}_{2}$ laser. In this process, the polyimide film's laser-irradiated area is converted to porous graphene, while the unexposed area remains unchanged. The temperature sensor manufactured by laser-induced graphene technology is shown in Figure 1(a), while the layer arrangement during the manufacturing process is shown in Figure 1(b). Finally, the hydrosol tape is dissolved with clean water to separate the processed LIG temperature sensor from the double-sided tape. The sensor can be removed entirely from the acrylic 


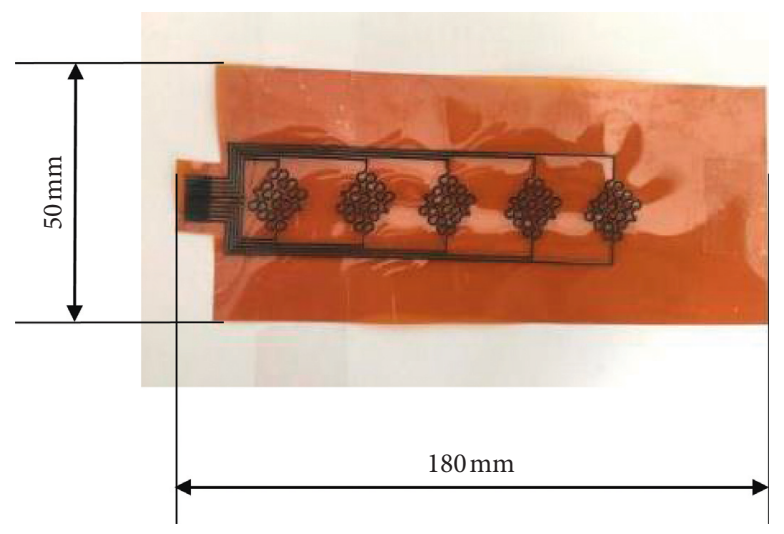

(a)
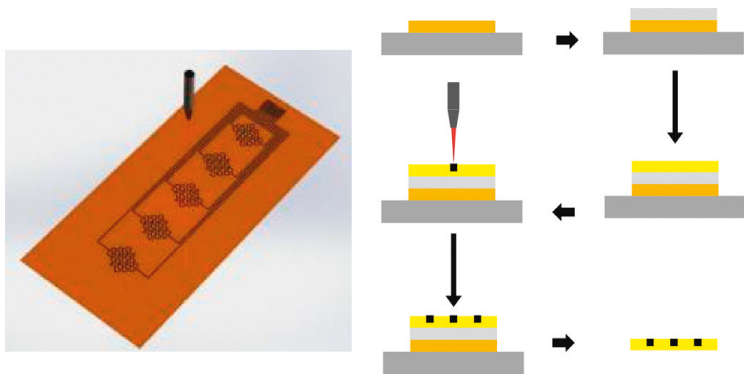

(b)

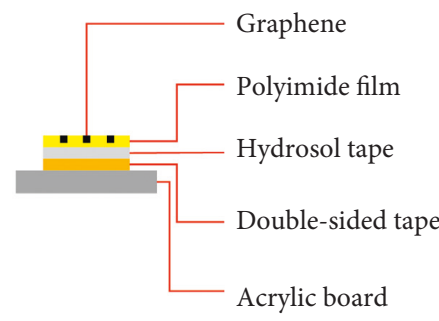

Acrylic board

Figure 1: (a) LIG temperature sensor; (b) LIG temperature sensor manufacturing process.

board without causing any damage or falling off to the sensor due to improper force. The whole manufacturing process is simple, quick, and does not require any other complicated, expensive, and time-consuming equipment.

Linet al. researched the laser-induced method to produce a porous graphene film. Founding that graphene manufactured by laser with $2.4 \mathrm{~W}-5.4 \mathrm{~W}$ power, the $G$ peak intensity ratio to the $D$ peak of the Raman spectrum $\left(I_{G} / I_{D}\right)$ shows that when the power rises to $4.8 \mathrm{~W}$, the graphene crystal size $\left(L_{a}\right)$ increases to $40 \mathrm{~nm}$. When the power continues to increases, the $L_{a}$ value will gradually decrease, and the higher the $L_{a}$ value, the lower the graphene porosity and the better the graphene quality [24]. In this research, the laser parameter during the fabrication process was chosen as follows: laser power of $4.8 \mathrm{~W}$, scanning speed of $3.5 \mathrm{inch} / \mathrm{s}$, and beam size of $120 \mu \mathrm{m}$, and the pattern adopts a serpentine layout to improve its stretchability.

\section{Experiment}

3.1. Raman Spectroscopy Test. This paper uses this test to characterize the final composition to decide whether the formed material is graphene. The Raman spectroscopy was measured by employing a Raman microscope excited by a $514 \mathrm{~nm}$ laser at room temperature.

\subsection{LIG Sensor Temperature Response for Different Conditions}

3.2.1. The Response of LIG between $30^{\circ} \mathrm{C}$ and $40^{\circ} \mathrm{C}$ (Simulate the Human Body Temperature Limits). In a room temperature environment of $27^{\circ} \mathrm{C}$, the LIG sensor was fixed on the constant temperature table's surface, as shown in Figure 2. The temperature table was used to provide the temperature change from $30^{\circ} \mathrm{C}$ to $40^{\circ} \mathrm{C}$, and the thermoelectricity was used to characterize the surface temperature of the temperature table. An Agilent 3458A digital multimeter was used to read the resistance value of the LIG sensor. After the table's temperature becomes stabilized, the multimeter's value was recorded, and the thermocouple's value for each $1^{\circ} \mathrm{C}$ changes for $10 \mathrm{~s}$. And then, the average value of these $10 \mathrm{~s}$ was found. The temperature table was used to replace the human body's surface temperature measurement. This experiment simulates the human body's measurement in an air-conditioned room with no wind, and the room temperature is $27^{\circ} \mathrm{C}$.

3.2.2. LIG Sensor Temperature Response between $30^{\circ} \mathrm{C}$ and $60^{\circ} \mathrm{C}$ (to Check the Stability in High Temperature). Using A-section equipment and the same measurement method, the effect of the temperature change on LIG sensor resistance between $30^{\circ} \mathrm{C}-60^{\circ} \mathrm{C}$ was studied. For every $5^{\circ} \mathrm{C}$, the 

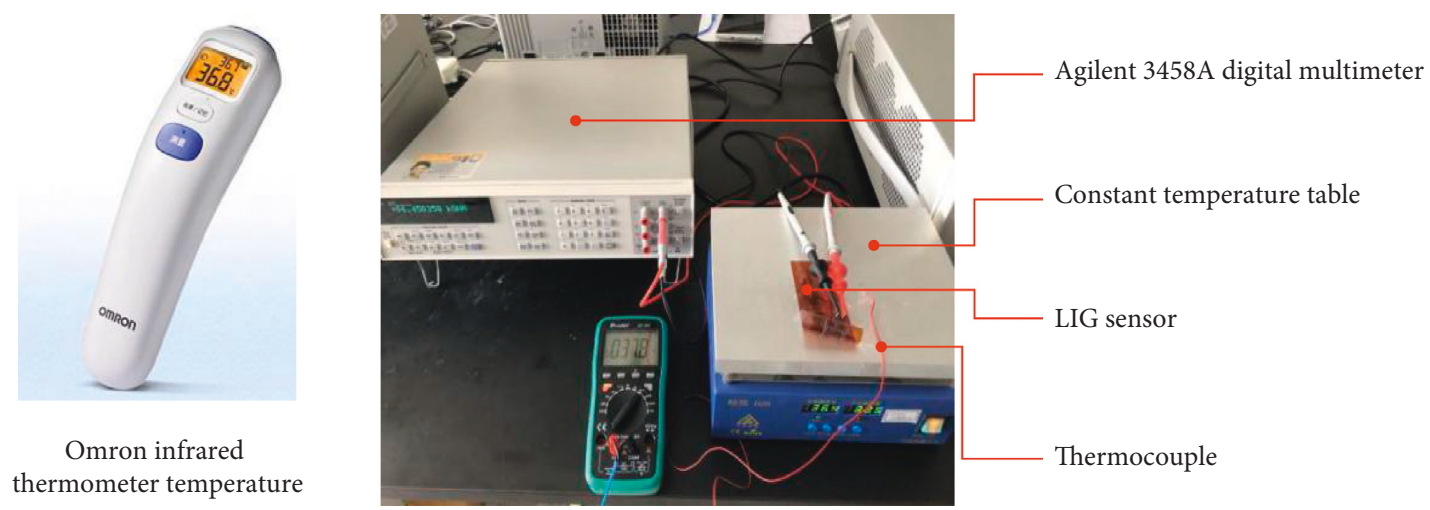

FIgURE 2: Temperature response test method of the sensor.

temperature was recorded by a thermocouple, and a multimeter recorded LIG sensor resistance. All the recordings last for the $30 \mathrm{~s}$ after the temperature table has reached the stabilized region, and then the average temperature value of the thermocouple reading was calculated.

\subsection{Practical Application and Sensor Accuracy Verification}

3.3.1. LIG Sensor Experiment for Human Body Temperature Measurement. In this experiment, three volunteers with age between 20 and 30 years and a normal body temperature in the last seven days, without any other symptoms, participated actively for a body temperature measurement using LIG sensors. Volunteers were asked to have nostrenuous exercise within 30 minutes before the test. Nor stayed in a room environment with a temperature above $30^{\circ} \mathrm{C}$ or below $20^{\circ} \mathrm{C}$. The data acquisition part was divided into two parts. (1) The volunteer's palm's body temperature was measured. The resistance of the LIG sensor was measured using a multimeter. And each person was collected data four times. The resistance was recorded within $10 \mathrm{~s}$ after the LIG sensor was contacted to the skin. Each time the measurement interval was $30 \mathrm{~s}$. The resistance value was converted into the corresponding temperature value by the fitting curve obtained in the A-section experiment. Before starting the experiment, each volunteer's temperature was measured with a thermocouple and compared with the LIG measurement result. (2) One of the volunteers was selected, and then the volunteers' palm's temperature was collected, and the LIG sensor's resistance value was recorded with a multimeter. $2 \mathrm{~s}$ before the sensor contacts the skin started to record the LIG sensor's resistance during the whole process of the sensor resistance from contacting the skin to leaving the skin.

3.3.2. Sensor Accuracy Verification Using LIG Sensor vs. Infrared Electronic Thermometer for Temperature Range $30^{\circ} \mathrm{C}-40^{\circ} \mathrm{C}$. The temperature collected from thermocouple of K-type with a range of $-20^{\circ} \mathrm{C}$ to $400^{\circ} \mathrm{C}$ and resolution of $0.1^{\circ} \mathrm{C}$ was taken as reference temperature to compare the LIG sensor and the most recent accurate infrared electronic thermometer of type Omron infrared. Because the human body temperature change is limited with time and the human body temperature cannot be controlled, the temperature table shown in Figure 2 was used to provide the needed temperature environment. By recording the thermocouple's temperature, Omron infrared thermometer temperature, and compared them with the LIG sensor resistance values, and got the LIG sensor's accuracy. The LIG sensor's resistance value was converted by the temperature response function obtained in Section 3.2.1 to get the temperature value which is calculated by this formula $R=S \times T+B$ (where $R$ is the resistance, $S$ is the sensitivity, and $T$ is the temperature). The temperature of the temperature table's surface cannot be measured with an infrared thermometer since the temperature table's surface is a metal surface. Because silica gel has good thermal conductivity, the ecoglex 00-35 fast platinum cured silica gel authorized by American smooth-on was used to prepare a silicone sheet with a thickness of $0.7 \mathrm{~mm}$ as a contacting material between the temperature table and the infrared thermometer. The silicone sheet surface temperature was measured using a thermocouple to check if there is any difference between the temperature on the silicone sheet surface and the temperature table surface. The results show that the surface temperature of silica gel is the same as that of the constant temperature table. Therefore, the silica gel sheet can be used as contacting material between the temperature table and the Omron infrared thermometer. Finally, every five measurements of the infrared thermometer were used to find the average temperature and plot the average measured values. The resistance values of the LIG sensor were also plotted into a graph.

\section{Result and Discussion}

4.1. Raman Spectroscopy Test Result. The Raman spectrum test result is shown in Figure 3, which has three peaks of the Raman spectrum that indicates the formed structure is graphene material: the $D$ peak at $1346 \mathrm{~cm}^{-1}$, the $G$ peak at $1580 \mathrm{~cm}^{-1}$, and the $2 \mathrm{D}$ peak at $2692 \mathrm{~cm}^{-1}$. Peak $D$ shows defects of graphene. The intensity of $G$ peak is higher than that of the $2 \mathrm{D}$ peak, indicating that the graphene has fewer layers. The value of $D / G$ is low, which indicates that its crystallinity is high. 


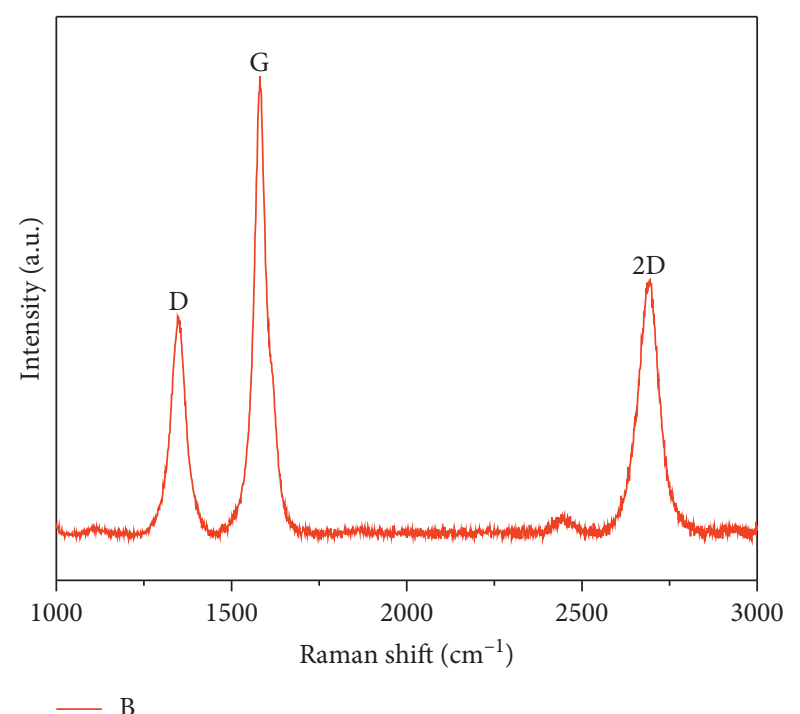

Figure 3: Raman spectrum.

4.2. Results of LIG Sensor Temperature Response between $30^{\circ} \mathrm{C}$ and $40^{\circ} \mathrm{C}$ Using Temperature Table. As shown in Figure 4, the $X$-axis represents the thermocouple's temperature value. The $Y$-axis represents the resistance value of the LIG sensor measured with a multimeter between $30^{\circ} \mathrm{C}$ and $40^{\circ} \mathrm{C}$. The relationship between the resistance of the LIG sensor and the temperature is linearly related. The value shows a linear decrease trend with the increase in temperature. The sensitivity is $-0.04145 \%{ }^{\circ} \mathrm{C}^{-1}$. And the fitted straight line's slopeintercept is $1.29049 \%$, indicating the LIG sensor's negative temperature coefficient characteristic.

\subsection{Experimental Results of LIG Sensor Temperature Response} between $30^{\circ} \mathrm{C}$ and $60^{\circ} \mathrm{C}$. As shown in Figure 5, the $X$-axis represents time and the $Y$-axis represents the resistance measured by the multimeter between $30^{\circ} \mathrm{C}$ and $60^{\circ} \mathrm{C}$. The resistance of the sensor is stable at each temperature, especially between $30^{\circ} \mathrm{C}$ and $40^{\circ} \mathrm{C}$, with no fluctuation. From $45^{\circ} \mathrm{C}$, the fluctuation gradually increases. Because the LIG sensor is used to measure the human body temperature, which changes between $31^{\circ} \mathrm{C}$ and $39^{\circ} \mathrm{C}$, the sensor is stable in this temperature range. As shown in Figure 5, the resistance of the LIG sensor is stable at $30^{\circ} \mathrm{C}, 35^{\circ} \mathrm{C}$, and $40^{\circ} \mathrm{C}$, which is measured between $(0,10),(10,20)$, and $(20,30)$, respectively. When the temperature rises above $40^{\circ} \mathrm{C}$, there is a slight gradual fluctuation in the resistance.

\subsection{LIG Sensor Practical Application Experimental Results}

(1) As shown in Table 1, the table records the four measurements of three volunteers' body temperature measured by using the LIG sensor and one measurement using the thermocouple k-type before the experiment. The results of the four measurements are within $\pm 0.55^{\circ} \mathrm{C}$ of the correct measured value by the thermocouple. The experimental results show that the LIG sensor has high stability and can measure the human body temperature.

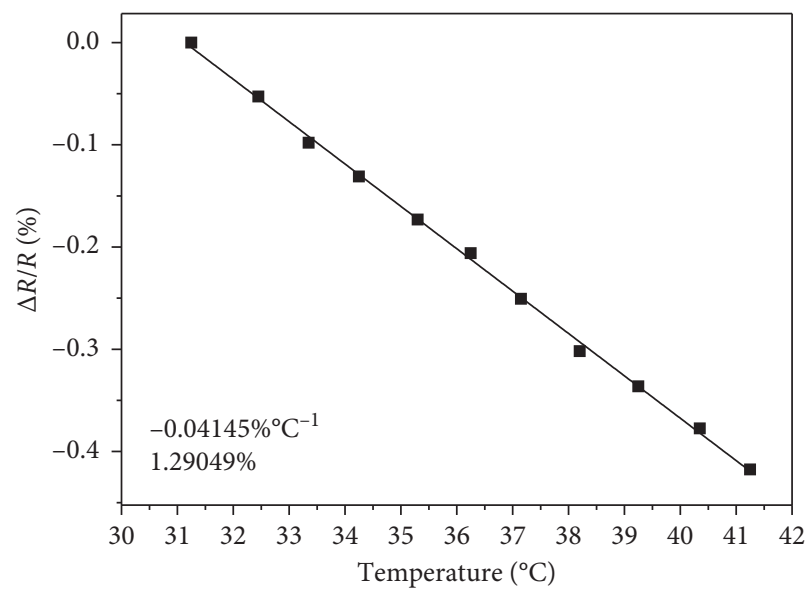

FIgURE 4: Linear relationship between the temperature and the LIG sensor resistance between $30^{\circ} \mathrm{C}$ and $40^{\circ} \mathrm{C}$.

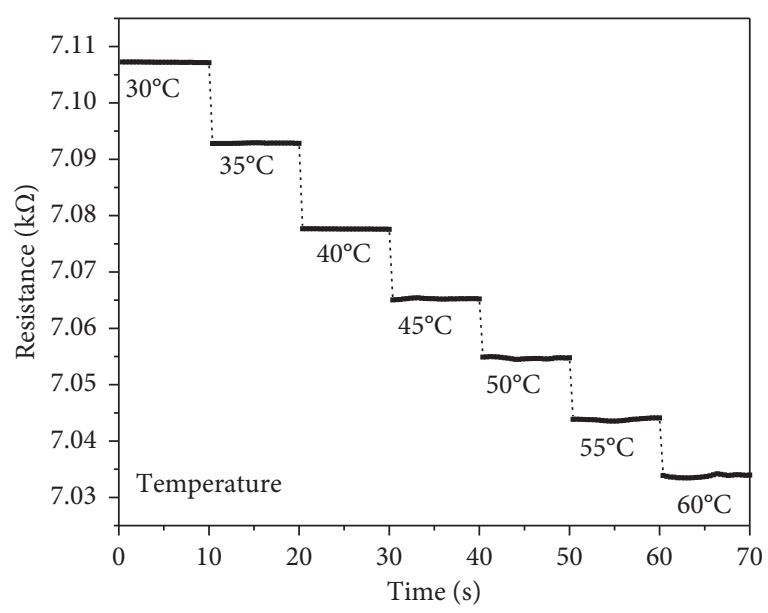

FIGURE 5: The relationship between the temperature and the LIG sensor resistance corresponding to the time.

(2) As shown in Figure 6, the abscissa is the time, and the ordinate is the sensor's resistance value-the time when the sensor contacts and leaves the skin has been indicated in the figure. The experimental results show that the time from skin contact to resistance temperature stabilization is about 30 seconds.

\subsection{LIG Sensor and Infrared Electronic Thermometer Accuracy} Comparison in $30^{\circ} \mathrm{C}-40^{\circ} \mathrm{C}$. The LIG sensor's error is within $\pm 0.15^{\circ} \mathrm{C}$, and Omron's infrared temperature sensor error is within $\pm 0.3^{\circ} \mathrm{C}$, which shows that the LIG sensor is more accurate than the infrared temperature sensor between $30^{\circ} \mathrm{C}$ and $40^{\circ} \mathrm{C}$. Graphically, as shown in Figure 7, the thermocouple characterization value is linear represented by a green straight line. The LIG sensor's characterization value, represented by a black line, is approximately identical to the thermocouple characterization value. In contrast, the Omron infrared device readings are represented with a red line, which is less similar to the thermocouple characterization value than the LIG sensor, which indicates that the 
TABle 1: Experimental results of the LIG sensor.

\begin{tabular}{lccccc}
\hline Volunteers & $\begin{array}{c}\text { LIG sensor } \\
\text { 1st measurement }\left({ }^{\circ} \mathrm{C}\right)\end{array}$ & $\begin{array}{c}\text { LIG sensor } \\
\text { 2nd measurement }\left({ }^{\circ} \mathrm{C}\right)\end{array}$ & $\begin{array}{c}\text { LIG sensor } \\
\text { 3rd measurement }\left({ }^{\circ} \mathrm{C}\right)\end{array}$ & $\begin{array}{c}\text { LIG sensor 4th measurement }\left({ }^{\circ} \mathrm{C}\right) \\
\text { Thermocouple } \\
\text { temperature }\left({ }^{\circ} \mathrm{C}\right)\end{array}$ \\
\hline 1 & 32.537 & 32.165 & 32.015 & 32.493 & 32.4 \\
2 & 33.523 & 32.904 & 33.940 & 33.598 \\
3 & 33.697 & 33.950 & 33.125 & 33.180 & 33.4 \\
\hline
\end{tabular}

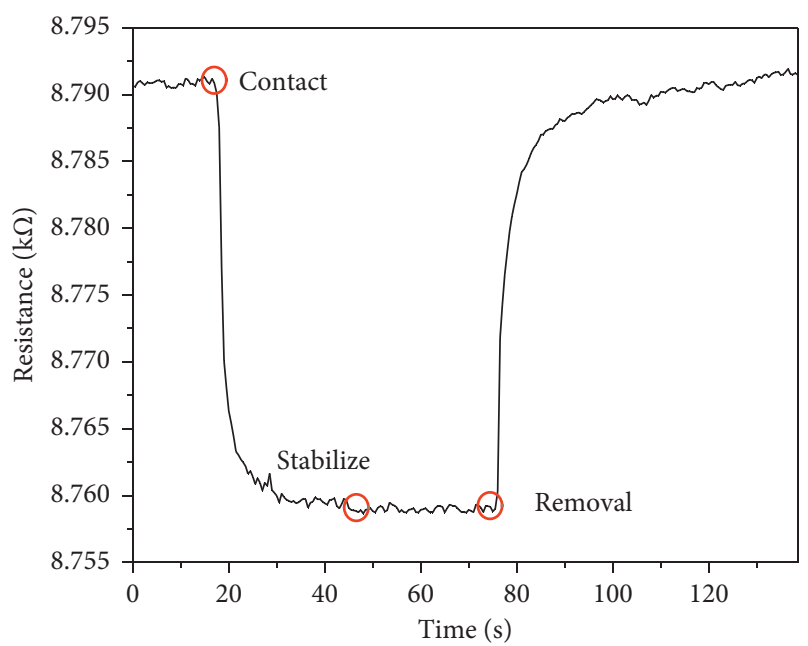

FIGURE 6: Experimental response time of the sensor in contact with skin to the time.

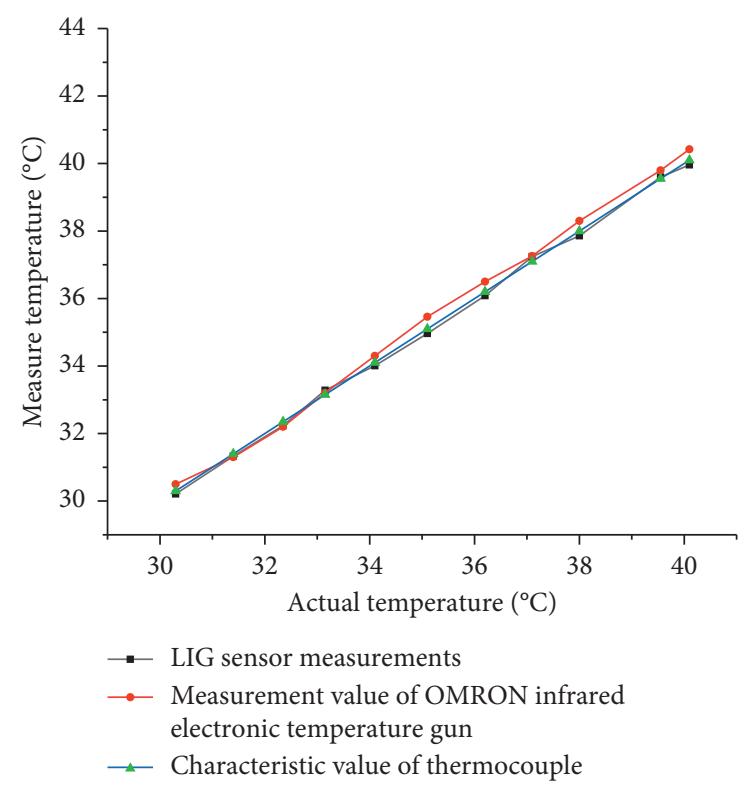

Figure 7: Comparison test results of LIG sensor measurement.

measurement result of LIG between $30^{\circ} \mathrm{C}$ and $40^{\circ} \mathrm{C}$ is more accurate than the measurement result of the Omron infrared temperature sensor.

4.6. Discussion. From the results in Sections 4.2 and 4.3, it can be seen that the resistance value of LIG sensor is linearly related to a temperature between $30^{\circ} \mathrm{C}$ and $40^{\circ} \mathrm{C}$, showing a negative temperature coefficient characteristic. From the results in Section 4.3, the resistance value is stable and accurate in a wide temperature range of $30^{\circ} \mathrm{C}-60^{\circ} \mathrm{C}$, and there is no apparent fluctuation. Section 4.5 shows that comparing the LIG sensor with the more precise infrared thermometers, the LIG sensor is more accurate with a range of $T \pm 0.15^{\circ} \mathrm{C}$. In contrast, the accuracy range of the infrared thermometer is $T \pm 0.3^{\circ} \mathrm{C}$. Section 4.4 shows that the LIG sensor can measure human body surface temperature.

\section{Conclusion}

In this paper, laser-induced graphene is used to manufacture a new type of temperature sensor that is fast, efficient, low cost, and simple in process, which can measure the human body's surface temperature with accurate measurement results. The LIG sensor is manufactured by $\mathrm{CO}_{2}$ laser-induced graphene, and the manufacturing process is simple, and the manufacturing method is easy to operate, and it is easy to achieve mass production. Experiments have been made to prove that the sensor has an accurate and stable response to temperature. It can be used to precisely measure the human body's surface temperature with accuracy $\left(T \pm 0.15^{\circ} \mathrm{C}\right)$.

\section{Data Availability}

The data used to support the findings of this study are available from the corresponding author upon request.

\section{Conflicts of Interest}

The authors declare that they have no conflicts of interest.

\section{Authors' Contributions}

Huang Kun and Liu Bin contributed equally to this paper.

\section{Acknowledgments}

The authors would like to thank the National Key R\&D Program of China (grant nos. 2020YFC2007402, 2020YFC2007404, and 2020YFC2007400), Jiangsu Province Frontier Leading Technology Fundamental Research Special Project "Multimodal Emotion Synthesis and HumanComputer Interaction Research on Cloud Fusion" (project no. BK20192004C), Jiangsu Province Science and Technology Project "Simulation Research and Experimental Platform Research and Development of the Functional Characteristics of Exoskeleton Robots" (grant no. BE2017007-2), International Partnership Program of the Chinese Academy of Science (grant no. 154232KYSB20200016), Suzhou Science and Technology 
Support Project (grant no. SYG201905), and National Key Research and Development Program of China (grant no. 2020YFC2007400) for their support.

\section{References}

[1] B. J. Zhang, S. H. Li, P. J. Du et al., "The most suitable time to measure the body temperature for inpatients," Chinese General Practice, vol. 6, no. 4, pp. 284-285, 2003.

[2] D. M. Wan, K. Yang, Y. Y. Zhang et al., "Design of temperature measurement system based on negative temperature coefficient," China Medical Devices, vol. 3, no. 11, pp. 98-103, 2017.

[3] A. H. Yu, X. H. Bi, and J. P. Zhang, "Prevention of mercury contamination of sphygmomanometers and thermometers," Chinese Journal of Nosocomiology, vol. 16, no. 2, p. 223, 2006.

[4] C. Deng, W. Hu, S. X. Diao et al., "Measurement error analysis and calibration technique of NTC-based body temperature sensor," Chinese Journal of Medical Instrumentation, vol. 39, no. 6, pp. 395-399, 2015.

[5] P. Zhang, F. Wang, S. Yang, G. Wang, M. Yu, and X. Feng, "Flexible in-plane micro-supercapacitors: progresses and challenges in fabrication and applications," Energy Storage Materials, vol. 28, pp. 160-187, 2020.

[6] D.-H. Kim, J.-H. Ahn, W. M. Choi et al., "Stretchable and foldable silicon integrated circuits," Science, vol. 320, no. 5875, pp. 507-511, 2008.

[7] Y. T. Wu and Z. J. Pan, "The research status and development tendency of flexible wearable electronic sensors," Modern Silk Science \& Technology, vol. 34, no. 5, pp. 22-25, 2019.

[8] H. Y. Liu and Y. Chen, "Research on application of flexible wearable strain sensor in human motion monitoring," Adhesion, vol. 43, no. 7, pp. 142-145, 2020.

[9] N. Luo, J. Ding, N. Zhao, B. H. K. Leung, and C. C. Y. Poon, "Mobile health: design of flexible and stretchable electrophysiological sensors for wearable healthcare systems," in Proceedings of the 2014 11th International Conference on Wearable and Implantable Body Sensor Networks, Zurich, Switzerland, 2014.

[10] T. Roland, K. Wimberger, S. Amsuess, M. F. Russold, and W. Baumgartner, "An insulated flexible sensor for stable electromyography detection: applicationto prosthesis control," Sensors (Basel, Switzerland), vol. 19, no. 4, 2019.

[11] S. W. Byun and S. P. Lee, "Implementation of hand gesture recognition device applicable to smart watch based on flexible epidermal tactile sensor array," Micromachines, vol. 10, no. 10, 2019.

[12] T. Sekitani, S. Yoshimoto, T. Araki, and T. Uemura, "A sheettype wireless electroencephalogram (EEG) sensor system using flexible and stretchable electronics," SID Symposium Digest of Technical Papers, vol. 48, no. 1, pp. 143-146, 2017.

[13] J. W. Gao, Q. B. Lu, L. Zheng et al., "Flexible sensing technology for bioelectricity," Materials Review, vol. 34, no. 1A, pp. 1095-1106, 2020.

[14] L. L. Wu, Flexible Temperature Sensor Based on Carbon Matrix Composite, Donghua University, Shanghai, China, 2020.

[15] X. Zeng, Research and Application of Flexible Temperature Sensor Based on PVDF/PEO, Hefei University of Technology, Hefei, China, 2019.

[16] M. D. Dankoco, G. Y. Tesfay, E. Benevent, and M. Bendahan, "Temperature sensor realized by inkjet printing process on flexible substrate," Materials Science and Engineering: B, vol. 205 , no. 3 , pp. $1-5,2016$.
[17] K. S. Karimov, F. A. Khalid, T. M. S. Chani et al., "Carbon nanotubes based flexible temperature sensors," Optoelectronics and Advanced Materials, vol. 6, no. 1-2, pp. 194-196, 2012.

[18] S. Y. Xiao, L. F. Che, X. X. Li et al., "Research on temperature sensor array based on flexible MEMS skin technology," Optics and Precision Engineering, vol. 13, no. 6, pp. 674-680, 2005.

[19] J. Peng, J. Li, W. Li et al., "Research progress and application of flexible wearable electronic strain sensor," New Chemical Materials, vol. 48, no. 1, pp. 57-62, 2020.

[20] C. Y. Wu, A Thesis Submitted in Fully Fulfillment of the Requirements for the Degree of Doctor of Engineering, Huazhong University of Science and Technology, Wuhan, China, 2019.

[21] W. J. Zhu, Y. K. Chen, Z. K. Zhang et al., "In-situ packaging 3D printing process for stretchable flexible circuits," Journal of Mechanical Engineering, vol. 55, no. 15, pp. 64-70, 2019.

[22] Z. Chui, "Flexible hybrid electronics: manufacturing flexible electronics by printing technique," Materials Reports, vol. 34, no. 1, 01013 pages, 2019.

[23] Z. P. Yin, Y. A. Huang, and N. B. Bu, "Flexible electronic printing manufacturing: materials, processes and equipment," Chinese Science Bulletin, vol. 34, no. 1, pp. 1009-1013, 2020.

[24] J. Lin, Z. Peng, Y. Liu et al., "Laser-induced porous graphene films from commercial polymers," Nature Communications, vol. 5, no. 1, p. 5714, 2014. 